\title{
Theoretical frameworks in researching mathematics teacher knowledge, practice, and development
}

\author{
J. P. da Ponte
}

Published online: 31 August 2013

(C) Springer Science+Business Media Dordrecht 2013

Interest in theory and theory building has been continuously increasing in mathematics education, including consideration of "grand theories," "middle range theories," and "local theories," depending on the scope of the domain of application (Silver and Hersbt 2007). In a recent reflection about research on and with mathematics teachers, Skott et al. (2013) underlined the importance of researchers making explicit theoretical and methodological assumptions.

While what is understood by "theory" in education research varies from author to author based on his or her perspective of what is being investigated and how to investigate it, there are specific factors that constitute a theory in the context of research. For example, Niss (2007) proposed that "a theory consists of an organized network of concepts ... and claims about some extensive domain, or a class of domains, consisting of objects, processes, situations, and phenomena" (p. 1308). A related concept is "framework," which seeks to describe the salient features and relationships between relevant concepts to describe a phenomenon, but making no claims about it.

Research in mathematics teacher education needs to draw on and use in a consistent way sophisticated theories and frameworks in order to deepen our collective understanding of the phenomena and situations with which we are concerned in this field. The three articles in this issue of the Journal of Mathematics Teacher Education are good examples of such use of theories and frameworks, in particular, in mathematics teacher education research. Robyn Pierce and Kaye Stacey used Everett Roger's theory for the diffusion of innovations and the "Pedagogical Opportunities Map" framework. Gunhan Caglayan used a theory of conceptual fields and frameworks of unit coordination, quantitative reasoning, adjectival quantities, and referent compositions. Edna Schack, Molly Fisher, Jonathan Thomas, Sara Eisenhardt, Janet Tassell, and Margaret Yoder used frameworks of professional noticing of children's mathematical thinking, pedagogies of practice, and "descriptive trajectory Stages of Early Arithmetic" in framing their studies. These are further highlighted in the following overview of each article.

J. P. da Ponte (西)

Instituto de Educação, Universidade de Lisboa, Lisbon, Portugal

e-mail: jpponte@ie.ul.pt 
The article by Pierce and Stacey analyzes how four recognized secondary school teachers introduced in their teaching practice new mathematics analysis software in the context of a school decision of adopting this technology. These teachers did not have a special interest in technology but constituted a very professional team, seeking to do their role in a very conscious way, including putting into practice school policy and collective decisions. To study this process, the authors combined a theory and a framework. They used Everett Roger's theory for the diffusion of innovations, which provides a view on the factors that influence the change or lack of change on the practice of the members of an organization - a middle range theory that may be applied to many phenomena of organizational change, within and outside education. This theory indicates the intrinsic characteristics of innovations that influence the decisions of participants to accept or reject the innovation. The authors also used a framework previously developed by themselves - the Pedagogical Opportunities Map - a taxonomy of the pedagogical opportunities in terms of the tasks that teachers propose to students, their desired style of classroom interaction, and the perspectives of mathematics that they promote. This framework, as it stands, concerns this particular software, and therefore, its applicability is limited to a narrow range of situations, giving a general picture of the teachers' perspectives and adoption of pedagogical opportunities.

The results of the study show that the teachers developed an increasing fluency in teaching with the technology, added new practices to their repertoire, and made some changes in the classroom didactic contract. The teachers took many of the challenges regarding the tasks to propose and the style of classroom interaction but few regarding the wider perspectives of mathematics. As the authors indicate, the global picture is that, more than changing practice, the new technology seemed to have been assimilated into current practice. This is consistent with the fact that, in this school, the teachers were generally satisfied with their teaching practice and did not have an agenda of changing it in a radical way. In addition, these teachers seemed to be uncomfortable with the rapid changes in technology that requires the need to learn new technical skills constantly and have no strong interest to consider in a deeper way the pedagogical opportunities that may be available. In this article, the more specific framework provides a detailed description of the phenomena, which structures the results section of the article, and the theory of diffusion of innovations provides the major foundation for the wider discussion given at the conclusion of the paper.

The article by Caglayan addresses prospective teachers' understanding of mathematics. Specifically, it deals with representational quantities generated by algebra tiles, with special attention to the underlying quantitative units and the quantitative operations of addition and multiplication acting on these quantities. The participants are two middle school and three secondary school prospective mathematics teachers. This study is supported by the theory of conceptual fields developed by Gérard Vergnaud, which stresses notions such as theorems in action and concepts in action, applied to the study of multiplicative structures. As the author indicates, this theory views the multiplicative structures, a conceptual field of multiplicative type, as a system of different but interrelated concepts, operations, and problems such as multiplication, division, fractions, ratios, and similarity. As a more specific theoretical framework, this article is based on the concepts of "units" and "quantities" as the essential ideas guiding this research study, drawing on the work of Les Steffe on unit coordination and Pat Thompson on quantitative reasoning. Also used is Judah Schwartz' framework on adjectival quantities and referent preserving/transforming compositions.

In this study, the results show that two prospective teachers made an additive interpretation of the context in a consistent way, whereas the other three could distinguish when 
they should make an additive or a multiplicative interpretation of the context. In the author's words, these results indicate that the identification and coordination of the representational quantities and their units at different categories (multiplicative, additive, pseudomultiplicative) are critical aspects of quantitative reasoning and need to be emphasized in the teaching-learning process. In this article, the notions provided by the theoretical frameworks were used to frame the interview tasks and questioning and as analytical devices for data analysis, whereas the general theory of conceptual fields and multiplicative structures provided the general setting to design the study and make sense of the results.

Finally, the article by Schack, Fisher, Thomas, Eisenhardt, Tassell, and Yoder deals with a study of prospective elementary school teachers' knowledge of mathematics teaching that involved ninety-four participants from three institutions that were attending their mathematics methods course. This study aimed to develop the participants' professional noticing abilities based on a five-session module that includes video excerpts of diagnostic interviews of children doing mathematics. The theoretical framework includes three main elements. First, it draws on a view of professional noticing of children's mathematical thinking, as defined by Jacobs, Lamb, and Philip, including the skills of attending to children's strategies, interpreting children's understandings, and deciding on teaching courses of action. Second, it is based on Grossmann, Compton, Igra, Ronfeldt, Shahan, and Williamson's framework of pedagogies of practice that includes representations of practice (such as video-clips with interviews with children doing mathematics), decomposition of practice (breaking practice into smaller components), and approximations of practice (including different kinds of activities, such as role-playing or diagnostic interviews). Third, it is based on the descriptive trajectory Stages of Early Arithmetic developed by Les Steffe, John Olive, and others that present a sequence of six levels of strategies children use to solve simple problems, with a characterization of each level, an indication of what it might look like, and a hallmark strategy.

The results of this study were obtained by codifying prospective teachers' responses into rank order data and performing nonparametric statistical tests. These results indicate that the module provided a significant growth in the prospective teachers' skills in all three components, showing that it may be useful to develop this competency in prospective mathematics teacher education. In this study, the Stages of Early Arithmetic framework provided the basis for the choice of the situations to include in the teacher education module and also a frame to assess the participants' responses, the pedagogies of practice framework provided the basis to design the different program sessions, and the professional noticing framework was also important to design the teacher education intervention as well as to provide the main structure for conceptualizing the outcome variables of interest.

Overall, in these studies, we see much more use of frameworks than theories. In Pierce and Stacey's study, the Pedagogical Opportunities Map is used to frame the research questions and first level of data analysis, whereas the theory for the diffusion of innovations is used for a more global analysis and interpretation of findings. Whereas the first is specific to mathematics teachers' perceptions and practice, the other has a much wider applicability to other professional groups and organizations.

In contrast, in the Caglayan study, the conceptual fields/multiplicative reasoning theory seems to be used to provide general guidance. In fact, in this study, the specific research questions and data analysis methods draw essentially on the frameworks of unit coordination, quantitative reasoning, adjectival quantities, and referent compositions. But neither the conceptual fields/multiplicative structures nor the units' coordination or quantitative 
reasoning frameworks are specific to study mathematics teachers-in fact, they were developed to study students' learning.

Finally, in the study of Schack et al., one of the frameworks, pedagogies of practice, is just used to set up the teacher education intervention, and the other two frameworks, professional noticing and Stages of Early Arithmetic, have the dual role of assisting this as well as to provide the structure for setting up the research questions and data analysis. In this case, one of the frameworks concerns students' learning, whereas the other two concern teacher competence and teacher education—-both probably with applicability to teachers of other subjects besides mathematics.

In almost all cases, the authors are borrowing the theories and frameworks from the research literature-the single exception is the Pierce and Stacey study that used a framework that the authors had previously developed and already considerably tested, which provided a reasonable guarantee of robustness and consistency. Also well proven based on their use in many previous studies are the frameworks of unit coordination, quantitative reasoning, adjectival quantities, and referent compositions used by Caglayan and the Stages of Early Arithmetic used by Schack et al. The same cannot be said of the professional noticing framework used by this latter group of authors, which is a recent formulation that may undergo further conceptual refinement. This explains the considerable work that these authors did on defining the categories for the analytical process, work that they still consider in progress, possibly leading to a reformulation of the categories or, at least, in their defining characteristics.

We must not be surprised by the little use of theories in these studies, since such theories, widely supported, are still very scarce in studies on the mathematics teachers' knowledge, practice, and development. It is a good sign that we see researchers using frameworks originally developed with other purposes, it is a better sign that some frameworks are related to teachers' competence and teacher education, and it is an even a better sign that we see the use of tested frameworks that address aspects of mathematics teacher's perceptions and practices, combining a wide range of phenomena, from classroom tasks and classroom interactions, to views of mathematics and educational goals. The studies in this issue of the journal, besides providing interesting examples of grounding the research in previous empirical work and using different analytical tools (qualitative and quantitative), show the way the field is taking toward the development and use of more sophisticated theoretical frameworks, some of which may be transformed in theories in a not too distant future.

\section{References}

Niss, M. (2007). Reflections on the state of and trends in research in mathematics teaching and learning: From here to Utopia. In F. Lester (Ed.), Second handbook of research on mathematics teaching and learning (pp. 1293-1312). Greenwhich: Information Age.

Silver, E., \& Hersbt, P. (2007). Theory in mathematics education scholarship. In F. Lester (Ed.), Second handbook of mathematics teaching and learning (pp. 39-67). Greenwich: Information Age.

Skott, J., Van Zoest, L. R., \& Gellert, U. (2013). Theoretical frameworks in research on and with mathematics teachers. ZDM Mathematics Education, 45, 501-505. 